\title{
The epidemiology of polymyalgia rheumatica in primary care: a research protocol
}

\author{
Sara Muller ${ }^{1 *}$, Samantha Hider ${ }^{1}$, Toby Helliwell ${ }^{1}$, Joanne Bailey ${ }^{1}$, Kevin Barraclough ${ }^{2}$, Louise Cope ${ }^{1}$, \\ Bhaskar Dasgupta ${ }^{3}$, Rebecca Foskett ${ }^{4}$, Rhian Hughes ${ }^{1}$, Zoe Mayson ${ }^{1}$, Charlotte Purcell ${ }^{1}$, Edward Roddy ${ }^{1}$, \\ Simon Wathall', Irena Zwierska ${ }^{1}$ and Christian D Mallen ${ }^{1}$
}

\begin{abstract}
Background: Polymyalgia Rheumatica (PMR) is the commonest inflammatory condition seen in older patients in primary care. To date, however, research has been focused on secondary care cohorts rather than primary care where many patients are exclusively managed. This two year prospective inception cohort study of PMR patients will enable us to understand the full spectrum of this condition.

Methods: Patients diagnosed with PMR in primary care will be identified via Read codes and mailed a series of postal questionnaires over a two-year period to assess their levels of pain, stiffness and functioning, as well as medication usage and other health-related and socio-demographic characteristics. In addition, participants will be asked for permission to link their survey data to their general practice electronic medical record and to national mortality and cancer registers.

Discussion: This will be the first large-scale, prospective, observational cohort of PMR patients in primary care. The combination of survey data with medical records and national registers will allow for a full investigation of the natural history and prognosis of this condition in the primary care setting, in which the majority of patients are treated, but where little research on the treatment and outcome of consultation has been undertaken. This will provide information that may lead to improved primary care management of PMR.
\end{abstract}

Keywords: Polymyalgia rheumatica, Primary health care, Cohort studies, Health surveys, Medical records

\section{Background}

In the UK, Polymyalgia Rheumatica (PMR) is the most common inflammatory rheumatic disease in adults aged 50 years and over, and is characterised by pain and stiffness in the shoulder and hip girdles and an elevated acute phase response [1]. On an international scale, the condition is known to increase with more Northerly latitude [2], but within the UK, PMR has been found to be more common in the South than in the North [3].

Whilst less common than other inflammatory arthropathies, such as Rheumatoid Arthritis, PMR is the commonest inflammatory disorder of older adults. In the UK, the estimated annual incidence is variable, ranging from $0.01 \%$ to $0.08 \%$ in those aged 40 years and over [3-5].

\footnotetext{
* Correspondence: s.muller@cphc.keele.ac.uk

${ }^{1}$ Arthritis Research UK Primary Care Centre, Primary Care Sciences, Keele University, Keele, Staffordshire ST5 5BG, UK

Full list of author information is available at the end of the article
}

Crowson et al [6] estimate the life-time risk of PMR in the US to be $2.4 \%$ for females and $1.7 \%$ for males. In the same population, the annual incidence has been estimated to be between $0.5 \%$ and $0.6 \%[7,8]$. With the ageing population [9], the number of patients with PMR is set to rise.

Health care systems vary between countries, but in the UK the majority of patients with PMR are managed exclusively in primary care $[5,10]$. Despite this, the majority of PMR research has been in the secondary care setting, which is likely to represent those with more severe disease than those managed solely in primary care. GPs are currently unable to offer their patients evidenced-based information regarding the prognosis of their condition, because there has not been a study of the course of PMR in primary care. Indeed, there is so little research examining the long-term prognosis of PMR, that there are no

\section{Biomed Central}

(c) 2012 Muller et al.; licensee BioMed Central Ltd. This is an Open Access article distributed under the terms of the Creative Commons Attribution License (http://creativecommons.org/licenses/by/2.0), which permits unrestricted use, distribution, and reproduction in any medium, provided the original work is properly cited. 
agreed patient-reported outcome measures and only recently has a definition of remission been suggested [11].

The recommended treatment for PMR is low dose corticosteroids, where the dose is tapered over a period of up to two years. This makes PMR one of the most common reasons for the long-term use of steroid therapy [1], and consequently has the potential to put PMR patients at increased risk of steroid-related complications, such as fractures and gastro-intestinal bleeding. Furthermore, there are some data to suggest that patients with PMR have increased mortality rates [12], although other studies have shown no such association [13].

Given the non-specific nature of some of the presenting symptoms such as joint pain and morning stiffness, recent diagnostic guidelines [1] have emphasised the need to exclude alternative diagnoses such as Rheumatoid Arthritis or malignancy, which may initially present in a similar manner and may also improve (at least in the early stages) with corticosteroid treatment. Little is known about the patterns of consultation of such patients or clinical predictors of PMR.

The long-term outcomes of patients with PMR are, largely unknown, particularly in the primary care population. This paper outlines the proposed protocol for an inception cohort of primary care patients receiving a diagnosis of PMR in the UK.

\section{Objectives}

The overall aim of this study is to assess the epidemiology of PMR in general practice.

Specific objectives in order to meet this aim include:

1. Describe the natural history and prognosis of PMR in primary care;

2. Identify the frequency of alternative diagnoses in those originally diagnosed with PMR;

3. Identify appropriate outcome measures for PMR in primary care;

4. Assess the association between PMR disease activity and quality of life;

5. Identify the patterns of PMR-related disability over a two-year period;

6. Describe the use of corticosteroids by patients with PMR over a two year period, and how this relates to pain and stiffness outcomes;

7. Assess clinical practice versus audit standards specified in British Society for Rheumatology [1] and the Royal College of Physicians [14] guidelines.

\section{Methods/design}

This study has received ethical approval from the Staffordshire Local Research Ethics Committee (REC reference number: 12/WM/0021).

\section{Design}

Prospective observational inception cohort recruited in UK primary care.

\section{Sampling frame}

All adults (aged $\geq 18$ years) registered with approximately 200 general practices, presenting at the practice and receiving a new Read-coded diagnosis of PMR between June 2012 and June 2014.

\section{Patient eligibility \\ Inclusion criteria}

- Aged 18 years and over.

- Registered with a participating general practice during the study period.

- First Read-coded consultation for PMR in the last three years occurred during the study period.

- Provided written informed consent to primary care medical record review.

\section{Exclusion criteria}

- Less than 18 years of age.

- Vulnerable groups, e.g. significant cognitive impairment, dementia, severe/terminal illness.

- Previous PMR diagnostic code in the last three years.

\section{Recruitment procedure \\ Patient identification}

Eligible patients will be identified via one of two methods: Method A and Method B. The different methods will be applied in different practices, according to practice preference and local recruitment systems. In both methods, when a patient consults with a new diagnosis of PMR and the general practitioner (GP) enters an appropriate PMR Read code (N20..), a pop-up window will appear, reminding the GP of the study. This window will request that, if they have not already done so, the GP orders the blood tests recommended for the diagnosis of PMR [1] and that they give the patient a postcard containing details of the study.

In Method A, in addition to the blood test and postcard reminder, the pop-up window will ask the GP to discuss the study with the patient and gain their consent to be contacted by the Research Centre. The GP will then be asked to complete a fax form and return to the Research Centre with the patient's name, gender, date of birth, address, NHS number, practice identifier and confirmation that he/she has a new diagnosis of PMR. On receipt of the fax by the Research Centre, the patient's details will be entered into a secure mailing database. The fax form will be stored in a secure filing cabinet. 
In Method B, practice staff or staff from the Primary Care Research Network (PCRN) will conduct fortnightly electronic searches of the primary care records in participating practices in order to identify patients with a new diagnosis of PMR.

The patient identification process will not interfere with routine primary care management except in that all participating general practices will be provided with copies of the British Society for Rheumatology guidelines for the management of PMR [1] and encouraged to request the recommended blood tests.

\section{Initiating patient contact}

Eligible patients identified by Method A will be sent a Study Pack from the Research Centre, containing a cover letter and Participant Information Sheet inviting them to take part and giving further details about the study. The name, contact telephone number and email address of the Principal Investigator will be provided should potential participants have any questions regarding the study. The Study Pack will also contain a Baseline Questionnaire with Consent Form and a stamped addressed envelope. For patients identified through Method B, the study pack will be sent by the PCRN on behalf of the general practitioner and will contain an invitation letter from the practice, rather than the research team.

Participants returning their questionnaire and consent form will be logged on the database. Returning a completed baseline questionnaire will be taken to indicate consent to be mailed the follow-up questionnaires. Consent forms will be stored securely with the fax forms received from GPs.

\section{Non-responders}

Non-responders to the mailed Study Pack will be sent a Reminder Letter with repeat Baseline Questionnaire after three weeks. Non-responders after this reminder will be assumed not to have consented to take part and will not be contacted again.

\section{Follow-up procedure}

\section{Responders to Study Pack not consenting to medical record} review

Participants who return the completed baseline questionnaire but do not give consent to medical record review

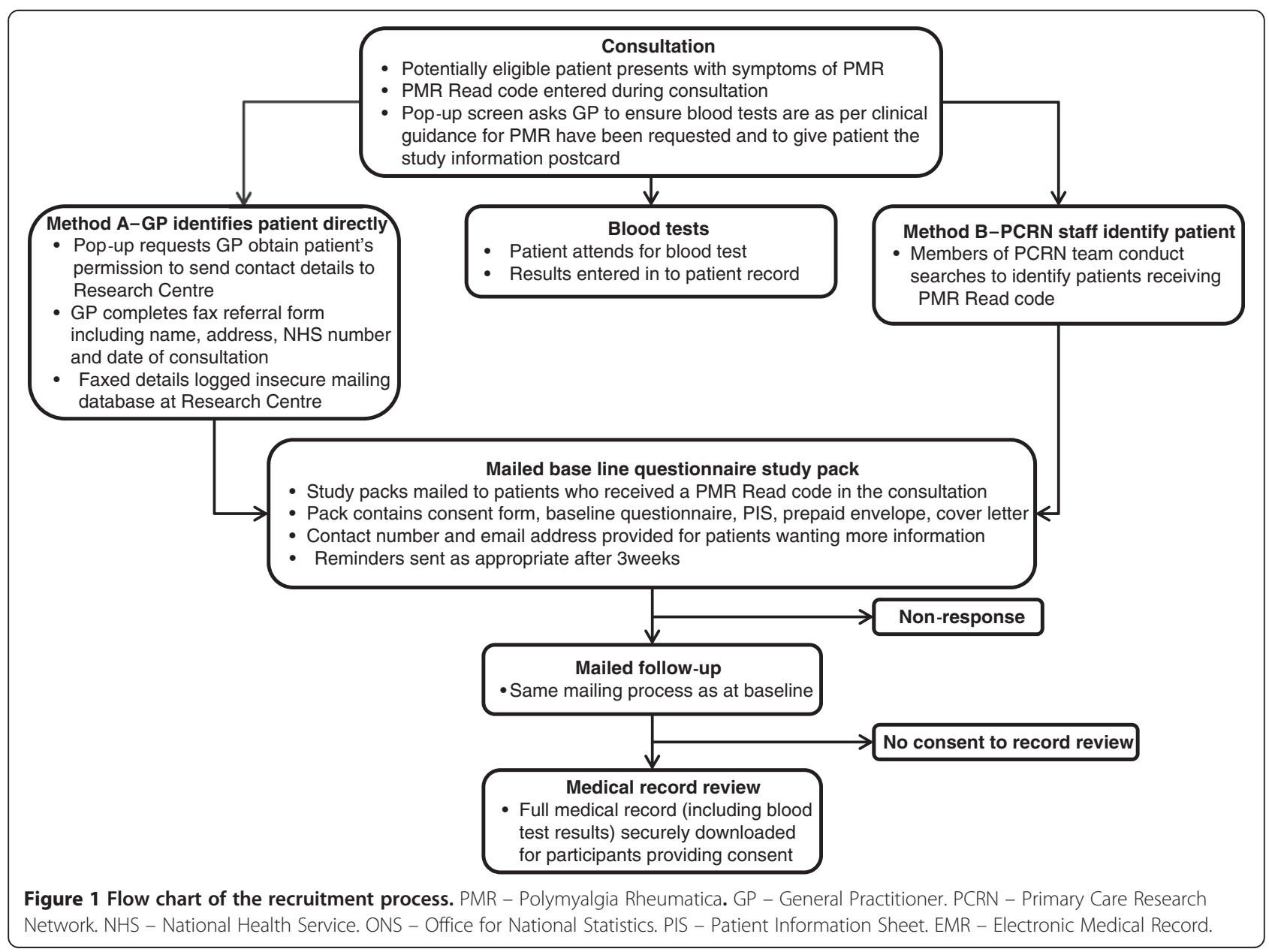


Table 1 Self-complete postal questionnaire. Conceptual domains, operational definitions and empirical measures

\begin{tabular}{|c|c|}
\hline Conceptual domain & Operational definition \\
\hline \multicolumn{2}{|l|}{ PMR symptoms } \\
\hline PMR-related pain & $\begin{array}{l}\text { Level of pain attributed to PMR } \\
\text { at time of questionnaire }\end{array}$ \\
\hline PMR-related stiffness & $\begin{array}{l}\text { Level of stiffness attributed to PMR } \\
\text { at time of questionnaire }\end{array}$ \\
\hline $\begin{array}{l}\text { Pain and stiffness } \\
\text { locations }\end{array}$ & $\begin{array}{l}\text { Pain shaded in hips and shoulders } \\
\text { to define PMR. }\end{array}$ \\
\hline Daily stiffness pattern & $\begin{array}{l}\text { Periods of day with stiffness } \\
\text { in the past week }\end{array}$ \\
\hline Morning stiffness & $\begin{array}{l}\text { Duration of stiffness from time of } \\
\text { waking in the past week }\end{array}$ \\
\hline $\begin{array}{l}\text { Delay in patient } \\
\text { consultation }\end{array}$ & Symptom chronicity at presentation to GP \\
\hline Delay in GP diagnosis & $\begin{array}{l}\text { Number of consultations with GP } \\
\text { before receiving diagnosis }\end{array}$ \\
\hline Shoulder movement & $\begin{array}{l}\text { Ability to raise both arms above head } \\
\text { at time of questionnaire }\end{array}$ \\
\hline $\begin{array}{l}\text { Patient perceived } \\
\text { recovery }\end{array}$ & Patient's self-perceived rating of recovery \\
\hline \multicolumn{2}{|l|}{ PMR Medications } \\
\hline Corticosteroid dose & Current daily dose of prednisolone \\
\hline Other medication use & $\begin{array}{l}\text { Reported use of (i) Paracetamol, } \\
\text { (ii) paracetamol + codeine, (iii) non-steroidal } \\
\text { anti-inflammatories, (iv) strong analgesics, } \\
\text { (v) gastro-intestinal protection, } \\
\text { (vi) calcium + vitamin D, (vii) osteoporosis } \\
\text { treatment, (viii) alternative therapies, } \\
\text { (ix) anti-depressants, (x) other }\end{array}$ \\
\hline
\end{tabular}

Empirical measure

\author{
Numerical rating scale $(0-10)$ of pain \\ intensity \\ Numerical rating scale $(0-10)$ of \\ stiffness \\ Manikin (Figure 2) \\ None/Morning/Lunchtime/ \\ Afternoon/Early evening/ Late
}

evening/During the night

None/1 to 15 minutes/16 to 45 minutes/ 46 minutes to an hour/More than an hour

Less than a week/1 to 2 weeks/

2 to 4 weeks/More than 4 weeks

$1 / 2 / 3 / 4$ or more

Yes/No

6 category scale (Completely recovered through to Much worse)

Number of Time items

point

ALL

ALL

ALL

ALL

ALL

BL

$B L$

ALL

$1 \mathrm{FU}, 4 \mathrm{FU}$, $8 \mathrm{FU}, 12 \mathrm{FU}$, 18FU, 24FU

Free text

Yes/No(free text for Other)

1

ALL

10

$B L$

\section{General health and other medical problems}

General health

Falls

Osteoporosis

PMR exclusion symptoms

Dyspepsia

\section{Daily activities}

Activities of daily living

\section{Fatigue and sleep}

Fatigue
Self-rated health at time of questionnaire Global health rating

Falls in previous 12 months

Ever fractured (i) hip, (ii) wrist,

(iii) spine/vertebrae, (iv) other

Reports of recent (i) Sudden headache,

(ii) Tender scalp, (iii) Disturbed/double vision,

(iv) Jaw claudication, (v) Temperature,

(vi) Appetite loss, (vii) Unintentional weight loss, (viii) Joint swelling, (ix) Other

$\mathrm{BL}, 12 \mathrm{FU}$, 24FU ALL

$\mathrm{BL}, 12 \mathrm{FU}$, 24FU

$\mathrm{BL}, 12 \mathrm{FU}$, 24FU

Yes/No(free text for Other)

$\mathrm{BL}$ Illness Therapy-Fatigue (Version 4) [19]
Bothersomeness of dyspepsia symptoms (ulcer, wind, indigestion, heartburn) at time of questionnaire

Seeking of healthcare of dyspepsia symptoms (if present)

Not at all bothered/Bothered a little/ Bothered a lotDid not seek help/ Went to GP/Went to hospital/

Other type of care

Modified Health Assessment

8

ALL

(17] adapted to UK English [18]

Functional Assessment of Chronic

4FU, 12FU, 24FU $4 \mathrm{FU}, 12 \mathrm{FU}$, 24FU

Fatigue symptoms in past week $\mathrm{BL}, 1 \mathrm{FU}$, 12FU, 24FU 
Table 1 Self-complete postal questionnaire. Conceptual domains, operational definitions and empirical measures (Continued)

\begin{tabular}{|c|c|c|c|}
\hline Sleep & $\begin{array}{l}\text { Insomnia symptoms in past } 2 \text { weeks } \\
\text { (including Diagnostic and Statistical } \\
\text { Manual of Mental Disorders insomnia }\end{array}$ & Insomnia Severity Index [20] & 7 \\
\hline
\end{tabular}

\section{Anxiety and depression}

Generalised anxiety disorder

Anxiety symptoms in past two weeks

Depression symptoms in past two weeks

Generalized Anxiety Disorder-7 [21]

PHQ-8 [22]

8

Date of birth

Male/Female

White/Mixed, multiple ethnic groups/ Asian, Asian British/Black, African,

Caribbean, Black British/Other

Employment status Employment status at time of questionnaire

Work situation

Level of work at time of questionnaire (in those in reporting being employed as their employment status)

Socioeconomic status

Occupational class based on (i) current or (ii) most recent job title

\section{Lifestyle}

Smoking

Smoking status at time of questionnaire

Alcohol

Obesity

BMl at time of questionnaire

Frequency of drinking at time of questionnaire

Employed/ Unemployed, seeking work/ House-wife/Retired/Not working due to ill health/Other

Doing usual job/Working fewer hours/ Paid sick leave/Paid annual leave, holiday/ Doing lighter duties/Unpaid leave

Job title - categorised as manual/ non-manual according to SOC 2010 [23]

Never/Previous/Current

Daily or almost daily/

3 or 4 times a week

Once or twice a week/

1 to 3 times a month/

Special occasionsonly/Never

Height (m/ft)Weight (kg/st, lb)

Yes/No

Married/Separated/Divorced/Widowed/ Cohabiting/Single

Not applicable/Not at all/ Little bit/ Moderately/Quite a bit/Extremely (adapted from [24])

Yes/No/No need [25]Yes/No/No need

Availability of instrumental support Availability of emotional support

\section{Views on PMR and information on the condition}

Origin PMR
Information regarding
PMR

Cause of PMR

Information given by GPGP information from GP useful

Desire for more information from GP Searched elsewhere for information

Worries regarding PMR

Flares
Medications
Reducing medications
Side-effects of medication

Long-term consequences of PMR
Free text

Yes/NoYes/NoYes/NoYes/No

Yes/No

Yes/No

Yes/No

Yes/No

Yes/No

Yes/No
7

11

BLBL, 12FU, 24FU

$\mathrm{BL}, 1 \mathrm{FU}$,

12FU, 24FU

$\mathrm{BL}, 1 \mathrm{FU}$, 12FU, 24FU

ALL

ALL

$B L$

$\mathrm{BL}, 1 \mathrm{FU}$, $4 \mathrm{FU}, 12 \mathrm{FU}$, 18FU, 24FU

$\mathrm{BL}, 10 \mathrm{FU}$, 4FU, 12FU, 18FU, 24FU

BL

$B L$

$B L$

BL, 24FU

$\mathrm{BL}, 12 \mathrm{FU}$, 24FU

$\mathrm{BL}, 12 \mathrm{FU}$, 24FU 24FU

$B L$

$1111 \quad \mathrm{BL}$
$\mathrm{BL}, 12 \mathrm{FU}$, 
Table 1 Self-complete postal questionnaire. Conceptual domains, operational definitions and empirical measures (Continued)

\begin{tabular}{|c|c|c|c|c|}
\hline & Other & & & \\
\hline \multirow{8}{*}{$\begin{array}{l}\text { Potentially useful for } \\
\text { PMR patients in the } \\
\text { future }\end{array}$} & Information & Yes/No and Received Yes/No & 2 & \multirow[t]{8}{*}{ 24FU } \\
\hline & Medications & Yes/No and Received Yes/No & 2 & \\
\hline & \multirow[t]{2}{*}{ Alternative medications } & Yes/No and Received Yes/No & 2 & \\
\hline & & Yes/No and Received Yes/No & 2 & \\
\hline & Complementary therapies & $\begin{array}{l}\text { Yes/No and Received Yes/NoYes/No } \\
\text { and Received Yes/No }\end{array}$ & 2 & \\
\hline & Physiotherapy & Yes/No and Received Yes/No & 2 & \\
\hline & Referral to secondary care & & 2 & \\
\hline & Other & & & \\
\hline
\end{tabular}

$\mathrm{ALL}=$ All follow-ups; $\mathrm{BL}=$ Baseline; $1 \mathrm{FU}=1$-month follow-up; 4FU = 4-month follow-up; 8FU = 8-month follow-up; 12FU = 12-month follow-up; 18FU = 18-month follow-up; 24FU = 24-month follow-up.

will receive mailings of further questionnaires as described below, but will not have their medical record accessed.

\section{Consenting responders}

Participants who return their Baseline Questionnaire and provide written informed consent to medical record review will be sent a Follow-up Questionnaires at one, four, eight, 12, 18 and 24 months after Baseline. Their medical records will be accessed as described below.

A flowchart of the process of recruitment and followup is provided in Figure 1.

\section{Data collection}

\section{Medical record review}

Where electronic data quality and practicalities allow, full electronic medical records of consenting participants will be accessed and securely downloaded to obtain information on symptoms, diagnoses, prescriptions and referrals. This data will be downloaded for the two years prior to diagnosis and for the two years of follow-up after diagnosis. Where electronic coding is not routine practice, or where downloading of data is impractical, a research nurse from the PCRN will visit practices and record salient data using a standardised proforma.

For validation purposes, records will be reviewed by a rheumatologist for the six months following PMR diagnosis. This review will use recorded symptoms, blood test results and examine for alternative diagnoses (e.g. malignancy). This review will be based on recent guidance from European League Against Rheumatism-American College of Rheumatology concerning classification criteria for PMR [15].

\section{Self-complete postal questionnaires}

The self-complete postal questionnaires will provide information on the descriptive characteristics of participants,
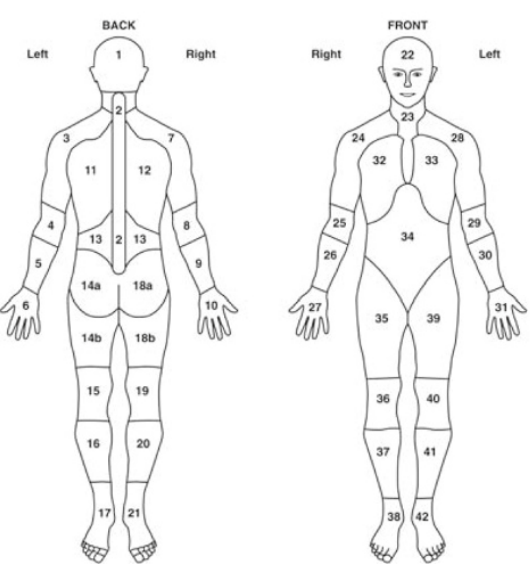

Mutually exclusive pain areas

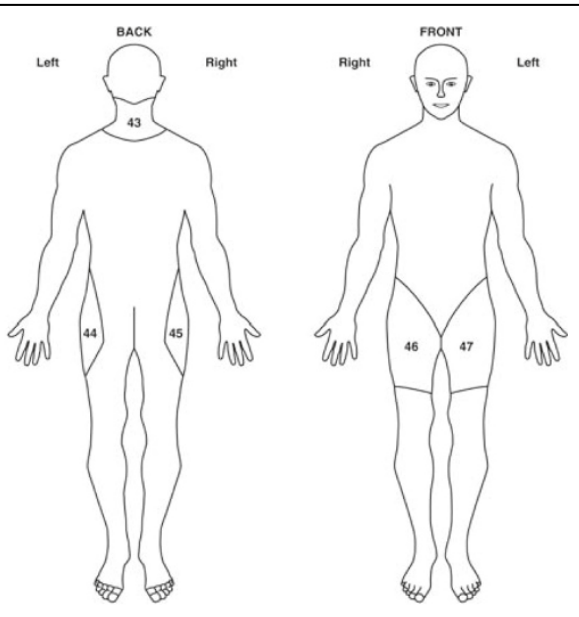

Neck and Hip Pain

Figure 2 Pain and stiffness manikins: definition of hips and shoulders. Shoulders are defined as areas 3, 7, 24 and 28. Hips are defined as areas $44,45,46$ and 47 [26]. 
outcome measurement, health care utilisation and more detailed prognostic information. The conceptual domains, operational definitions, and empirical measures used are provided in Table 1.

\section{Data entry, coding, cleaning and storage}

Data will be pseudonymised and entered into a database specifically designed for this study. Prior to data entry, this database will be tested using a set of dummy data. Data will be entered as the completed questionnaires are received by dedicated members of the administration team. They are experienced in data entry. The Principal Investigator will determine coding prior to data entry. The database will provide coding options, to facilitate the entry of data. Some standard codes (e.g. missing data (-9), not applicable $(-88)$ ) are used by the Research Centre and will be utilised in this study.

A different member of the team will then check every tenth questionnaire as part of the quality assessment process. This information is kept by the Research Support Co-ordinator. Data will be stored in a password protected database and overseen by the Study Data Custodian. Only members of the research team will have access to the data. Requests for access to the data must be made in writing, along with an analysis plan, to the Principal Investigator. Completed questionnaires will be securely stored separately from the fax and consent forms, to protect the confidentiality of participants.

\section{Sample size}

PMR is a relatively rare condition in primary care and so the size of this study is constrained by practicalities to ensure a representative sample of patients for whom good quality data can be collected. From the CiPCA database [27], it can be estimated that for every 10,000 primary care patients aged 40 years and over, approximately 11 will receive a diagnosis of PMR in a 12-month period (Kelvin Jordan - personal communication). Using a stricter definition to define PMR, similar to that to be applied in this study, Smeeth et al [3] estimated that 8 per 10,000 patients in this age group experience a new onset of PMR every year. With an average practice list size of 5,000 (approximately half of whom will be aged 40 years or over), a two-year recruitment period, in 200 practices should enable identification of 1,100 patients with a Read-coded diagnosis of PMR, of whom 800 would be expected to have definite PMR according to the Smeeth definition [3]. Based on previous experience of this type of study in our Research Centre [28,29], we expect that $75 \%$ of patients will respond to the questionnaire with $80 \%$ of these consenting to have their medical records reviewed. This will result in an initial sample of 600 patients, with 480 forming the cohort that has agreed to medical record review. Allowing for loss to follow-up of $5 \%$ per annum, this should leave a sample of approximately 430 patients at the end of the two year follow-up period.

\section{Statistical analysis}

A descriptive summary of those consenting and not consenting to join the cohort will be provided, as will a description of loss-to-follow-up in the cohort over the two years of the study.

The psychometric properties of the Modified Health Assessment Questionnaire (MHAQ) [17] will be investigated to assess its suitability for use in this population. The recently proposed clinical criteria for remission and relapse in PMR [11] will also be implemented to investigate their feasibility in primary care epidemiological studies.

With these findings in mind, regression models will be used to describe the natural history and prognosis of PMR over a two-year period. These models will take into account PMR-related disability, as well as quality of life, sexual functioning and work disability, and will incorporate both self-reported constructs and information derived from medical records. The average daily dose of corticosteroids will be calculated and modelled as a potential prognostic factor for disease activity and new onset comorbidities.

An overall prognostic model for the chosen outcome in PMR over two years will be derived and tested.

Where necessary, multiple imputation techniques will be used to assess the impact of loss-to-follow-up.

\section{Discussion}

To our knowledge, there has been no previous primary care inception cohort study of PMR. This study will fill this gap, by collecting detailed information via postal questionnaires and medical record review (where consent is given), from patients receiving a new primary care diagnosis of PMR. This study will provide guidance on the optimal methods of outcome assessment for PMR in primary care, and will develop new prognostic models, relevant to clinical practice in this group. This study should ultimately lead to improved outcomes for older patients diagnosed with this common inflammatory condition.

\section{Competing interests}

The authors declare that they have no competing interests.

\section{Acknowledgements}

CDM and the PMR Study are funded by a Clinician Scientist Fellowship from Arthritis Research UK. SM is supported by a Postdoctoral Fellowship from the NIHR NSPCR. TH is supported by an NIHR In-Practice Fellowship. We thank Dr Kelvin Jordan for his help in estimating the incidence rate of PMR in the CiPCA dataset. 


\section{Author details}

${ }^{1}$ Arthritis Research UK Primary Care Centre, Primary Care Sciences, Keele University, Keele, Staffordshire ST5 5BG, UK. ${ }^{2}$ Painswick Surgery, Hoyland House, Painswick, Gloucestershire GL6 6RD, UK. ${ }^{3}$ Southend University Hospital, Southend University Hospital NHS Foundation Trust, Prittlewell Chase, Westcliff-on-Sea, Essex SSO ORY, UK. ${ }^{4}$ Primary Care Research West Midlands North, Unit 2, Badhan Court, Telford TF1 5QX, UK.

\section{Authors' contributions}

CDM and SH conceived the idea for the study. All authors participated in the design of the study. SM drafted the manuscript, which was approved by all authors.

Received: 8 May 2012 Accepted: 15 June 2012

Published: 15 June 2012

\section{References}

1. Dasgupta B, Borg FA, Hassan N, Barraclough K, Bourke B, Fulcher J Hollywood J, Hutchings A, Kyle V, Nott J, Power M, Samanta A, BSR and BHPR Standards, Guidelines and Audit Working Group: BSR and BHPR guidelines for the management of polymyalgia rheumatica. Rheumatology (Oxford) 2010, 49:186-190.

2. Cimmino MA, Zaccaria A: Epidemiology of polymyalgia rheumatica. Clin Exp Rheumatol 2000, 18(Suppl 20):S9-S11.

3. Smeeth L, Cook C, Hall AJ: Incidence of diagnosed polymyalgia rheumatica and temporal arteritis in the United Kingdom, 1990-2001. Ann Rheum Dis 2006, 65:1093-1098.

4. Kyle V, Silverman B, Silman A, King H, Oswalkd N, Reiss B, Hazelman B: Polymyalgia rheumatica/giant cell arteritis in a Cambridge general practice. Br Med J 1985, 291:385-387.

5. Barraclough K, Liddell WG, du Toit J, Foy C, Dasgupta B, Thomas M, Hamilton W: Polymyalgia rheumatica in primary care: a cohort study of the diagnostic criteria and outcome. Fam Pract 2008, 25:328-333.

6. Crowson CS, Matteson EL, Myasoedova E, Michet CJ, Ernste FC, Warrington K, Davis JM 3rd, Hunder GG, Therneau TM, Gabriel SE: The lifetime risk of adult-onset rheumatoid arthritis and other inflammatory autoimmune rheumatic diseases. Arthritis Rheum 2011, 63:633-639.

7. Chuang TY, Hunder GG, Ilstrup DM, Kurland LT: Polymyalgia rheumatica: a 10-year epidemiologic and clinical study. Ann Intern Med 1982 97:672-680

8. Doran ME, Crowson CS, O'Fallon MW, Hunder GG, Gabriel SE: Trends in the incidence of polymyalgia rheumatica over a 30 year period in Olmsted County Minnesota, USA. J Rheumatol 2002, 29:1694-1697.

9. Christensen K, Doblhammer G, Rau R, Vaupel JW: Ageing populations: the challenges ahead. Lancet 2009, 374:1196-1208.

10. Chakravarty K, Elgabani SHS, Scott DGI, Merry P: A district audit on the management of polymyalgia rheumatica and giant cell arteritis. $\mathrm{Br}$ Rheumatol 1994, 33:152-156.

11. Dejaco C, Duftner C, Cimmino MA, Dasgupta B, Salvarani C, Crowson CS, Maradit-Kremers $\mathrm{H}$, Hutchings A, Matteson EL, Schirmer M, International Work Group for PMR and GCA: Definition of remission and relapse in polymyalgia rheumatica: data from a literature search compared with a Delphi-based expert consensus. Ann Rheum Dis 2011, 70:447-753.

12. Schaufelberger C, Bengtsson BA, Andersson R: Epidemiology and mortality in 220 patients with polymyalgia rheumatica. Br J Rheumatol 1995 34:261-264.

13. Myklebust G, Wilsgaard T, Jacobsen BK, Gran JT: Causes of death in polymyalgia rheumatica: A prospective longitudinal study of 315 cases and matched controls. Scand I Rheumatol 2003, 32:38-41.

14. Royal College of Physicians: Diagnosis and management of polymyalgia rheumatica. [http://www.rcplondon.ac.uk/sites/default/files/polymyalgiarheumatica-concise-guideline.pdf].

15. Dasgupta B, Cimmino MA, Maradit-Kremers H, Schmidt WA, Schirmer M, Salvarani C, Bachta A, Dejaco C, Duftner C, Jensen HS, Duhaut P, Poór G, Kaposi NP, Mandl P, Balint PV, Schmidt Z, lagnocco A, Nannini C, Cantini F, Macchioni P, Pipitone N, Amo MD, Espígol-Frigolé G, Cid MC, MartínezTaboada VM, Nordborg E, Direskeneli H, Aydin SZ, Ahmed K, Hazleman B, et al: 2012 provisional classification criteria for polymyalgia rheumatica: a European League Against Rheumatism/American College of Rheumatology collaborative initiative. Ann Rheum Dis 2012, 71:484-492.
16. The EuroQol Group: EuroQol-a new facility for the measurement of health-related quality of life. Health Policy 1990, 16:199-208.

17. Pincus T, Summey JA, Sorcai SA Jr, Wallston KA, Hummon NP: Assessment of patient satisfaction in activities of daily living using a modified Stanford Health Assessment Questionnaire. Arthrtis Rheum 1983, 26:1346-1353

18. Kerwan JR, Reeback JS: Stanford Health Assessment Questionnaire Modified to assess disability in British patients with rheumatoid arthritis. Br J Rheumatol 1986, 25:206-209.

19. Yellen SB, Cella DF, Webster K, Blendowski C, Kaplan E: Measuring fatigue and other anemia-related symptoms with the Functional Assessment of Cancer Therapy (FACT) Measurement System. J Pain Symptom Manage 1997, 13:63-74.

20. Morin CM: Insomnia: psychological assessment and management. New York: Guilford Press; 1993

21. Spitzer RL, Kroenke K, Williams JB, Löwe B: A brief measure for assessing generalized anxiety disorder: the GAD-7. Arch Intern Med 2006 166:1092-1097.

22. Kroenke K, Strine TW, Spitzer RL, Williams JBW, Berry JT, Mokdad AH: The PHQ-8 as a measure of current depression in the general population. $J$ Affective Disorders 2009, 114:163-173.

23. Office for National Statistics: Standard Occupational Classification 2010 (SOC2010).: ; [http://www.ons.gov.uk/about-statistics/classifications/current/ soc2010/index.html].

24. Haywood KL, Garratt AM, Jordan KP, Healey EL, Packham JC: Evaluation of ankylosing spondylitis quality of life (EASi-QoL): reliability and validity of a new patient-reported outcome measure. I Rheumatol 2010, 37:2100-2109.

25. Krumholz HM, Butler J, Miller J, Vaccarino V, Williams CS, de Leon CF Mendes, Seeman TE, Kasl SV, Berkman LF: Prognostic importance of emotional support for elderly patients hospitalized with heart failure. Circulation 1998, 97:958-964.

26. Birrell F, Croft P, Cooper C, Hosie G, Macfarlane GJ, Silman A, PCR Hip Study Group: Radiographic change is common in new presenters in primary care with hip pain. Rheumatology (Oxford) 2000, 39:772-775.

27. Jordan K, Clarke AM, Symmons DP, Fleming D, Porcheret M, Kadam UT, Croft P: Measuring disease prevalence: a comparison of musculoskeletal disease using four general practice consultation databases. $\mathrm{Br} I$ Gen Pract 2007, 57:7-14

28. Dunn KM, Jordan K, Croft PR: Characterizing the course of low back pain: a latent class analysis. Am J Epidemiol 2006, 163:754-761.

29. Mallen CD, Peat G, Thomas E, Wathall S, Whitehurst T, Clements C, Bailey J, Gray J, Croft PR: The assessment of the prognosis of musculoskeletal conditions in older adults presenting to general practice: a research protocol. BMC Musculoskelet Disord 2006, 7:84.

doi:10.1186/1471-2474-13-102

Cite this article as: Muller et al:: The epidemiology of polymyalgia rheumatica in primary care: a research protocol. BMC Musculoskeletal Disorders 2012 13:102.

\section{Submit your next manuscript to BioMed Central and take full advantage of:}

- Convenient online submission

- Thorough peer review

- No space constraints or color figure charges

- Immediate publication on acceptance

- Inclusion in PubMed, CAS, Scopus and Google Scholar

- Research which is freely available for redistribution 